\title{
A Race beyond the Bottom: The Nature of Bidding for a Firm*
}

\author{
Taiji Furusawa \\ Hitotsubashi University \\ Kazumi Hori \\ Ritsumeikan University \\ Ian Wooton ${ }^{\dagger}$ \\ University of Strathclyde, CESifo and CEPR
}

December 15, 2013

\begin{abstract}
We examine how the bidding environment may affect the outcome of tax competition between two countries (or two regions) in attracting a firm's foreign direct investment (FDI). We compare the equilibrium location choice and payoffs from an English auction, with both complete and incomplete information, relative to those in the traditional setting of a sealed-bid first-price auction. We find that an English auction leads to more aggressive bidding in "race beyond the bottom," where the nations may bid beyond their own valuations of the FDI. We also discuss the roles of auction protocol and information asymmetry on the auction outcome.
\end{abstract}

Keywords: tax competition; foreign direct investment; international ownership; English auction; information asymmetry.

JEL classifications: F12; F23; H25; H73.

To be published in International Tax and Public Finance.The final publication is available at Springer via http://dx.doi.org/10.1007/s10797-014-9326-Z

\footnotetext{
${ }^{*}$ We wish to thank Sebastian Klotz for his very able research assistance. We are also grateful to participants of seminars and presentations at the University of Nottingham, ETSG 2009 Rome, Hitotsubashi COE one-day trade workshop, Midwest International Trade Meetings at Notre Dame University and Loughborough University for their helpful comments. Furusawa acknowledges the financial support of the Global COE Hi-Stat (Hitotsubashi University) and the Abe Fellowship.

${ }^{\dagger}$ Corresponding author. Address: Department of Economics, University of Strathclyde, Sir William Duncan Building, 130 Rottenrow, Glasgow G4 0GE, United Kingdom. Telephone: +44 141548 3580. Fax: +44 141548 4445. Email: ian.wooton@strath.ac.uk.
} 


\section{Introduction}

It has been well documented that countries, states, or regional authorities bid to attract investments by giving generous tax incentives, investing in infrastructure, providing worker education opportunities or offering other benefits to the firms. ${ }^{1}$ The state of Georgia, for example, offered incentives to the value of $\$ 320$ million in its winning bid for DaimlerChrysler's assembly plant despite South Carolina having offered $\$ 346$ million in incentives in its attempt to lure the factory (New York Times, October 18, 2002). In another case, The Philippines made a generous offer to General Motors (GM), including free use of land in addition to tax and tariff cuts, but Thailand was the winner in luring GM's Asian motor-vehicle manufacturing base by waiving its domestic content requirements for the entire industry (Financial Post, May 30, 1996). ${ }^{2}$ The empirical relevance of bidding wars for firms is confirmed by Greenstone and Moretti (2004) and Devereux, Lockwood, and Redoano (2008), among others.

One of the most important results in the literature of tax competition is the phenomenon known as the "race to the bottom." With identical potential host nations bidding to attract a firm, each country is prepared to undercut its rival's offer such that, in equilibrium, all of the winning nation's gains from the foreign direct investment (FDI) are transferred to the firm. Thus the winning (host) country fares no better than the losing nation, despite receiving the investment. Haufler and Wooton (1999) show that the race to the bottom is slowed when one nation is larger than the other. Such a size asymmetry results in the larger country winning the bidding contest, as it is both more attractive to the investor and is prepared to pay a larger subsidy (or offer lower corporate taxation) in order to lure the FDI. Despite the larger country's greater willingness to pay to attract the FDI, it need only slightly improve upon the offer made by the rival, smaller country and thereby keeps some of the benefits of the FDI that would otherwise be captured by the firm.

Ferrett and Wooton (2010) use the same framework as Haufler and Wooton (1999) to explore whether ownership of the firm makes a difference to the equilibrium location or tax

\footnotetext{
${ }^{1}$ The terms "country", "nation" and "region" will be used interchangeably, as competition for FDI may be international or may take place between jurisdictions within an individual country.

${ }^{2}$ Davies (2005) lists various automotive plant incentive packages in Table 1 of his paper.
} 
rates. They investigate whether the assumption that the firm is owned entirely by individuals who do not live in either bidding country is critical to the outcome. This is an important question as most large firms in this globalized world are owned by shareholders who are geographically dispersed. As an example, in December 2012, 34.8\% of the shares of the Japanese electronics company, Canon, were held by foreign citizens. Similarly, the ratio of foreign shareholders in Sony was 32.7\% in March 2013. Intuitively, one might expect a country to bid more aggressively (offering bigger subsidies to the firm) when its citizens own a sizeable share of the firm, as much of the cost of the bid is merely a transfer from the government of the country to its shareholding citizens. However, Ferrett and Wooton (2010) establish an "invariance result" showing that the unique equilibrium of a tax/subsidy competition game between two governments is independent of the international distribution of the firm's ownership. Their result applies both to the equilibrium location of the firm's plant and to the countries' equilibrium tax/subsidy offers. Thus the nationality of the firm's owner is irrelevant to the strategy that a potential host country should follow in offering investment incentives. This conclusion is significant in that it means that the policymaker can simply ignore (or, indeed, never find out) the ownership of the firm. ${ }^{3}$

This argument, however, depends critically on the protocol of tax competition. As with Haufler and Wooton (1999), Ferrett and Wooton (2010) treat the bidding contest as a simultaneous bidding (or sealed-bid, first-price auction) under complete information. What is critical in this context is that raising a bid cannot induce a rival country to follow suit and further increase its offer. But, reality might not conform to this, with the possibility that regions might counter each otherĄfs bids with a better offer. In an English auction (or ascending-price auction), for example, an increase in one country's bid may induce its

\footnotetext{
${ }^{3}$ This "invariance result" can be understood with an example. Consider a situation in which Germany and France compete for a firm. Suppose that the two nations are equally attractive to the firm, so that the firm will choose the country that offers the higher bid. We further assume that German shareholders hold $30 \%$ and French shareholders hold $20 \%$ of the firm's shares. Let France offer $€ 100$ million incentives to the firm while Germany improves slightly upon this offer and wins. In doing so, German shareholders have lost $€ 30$ million, their share of the French offer had it been successful. But at the same time, these German shareholder receive $€ 30$ million out of the $€ 100$ million paid by their own government. Similarly, French shareholders get $€ 20$ million regardless of which country wins. Thus, on balance, the shareholders are unaffected by whichever country's bid is successful in attracting the FDI. Consequently, the fact that the bidding countries own shares in the firm does not change the outcome of the tax competition.
} 
rival to respond with a improvement on its own bid, driving up the incentives offered to the firm for its investment. In this paper, we examine the impact on the bidding equilibrium of changing the contest from the sealed-bid auction of the existing literature to that of an English auction.

It is difficult to establish exactly what happens in reality, as bidding wars are often shrouded in secrecy with limited information being made available during the bidding process (and, indeed, after the deals are done). Ideally, we would like to find clear evidence of the dominance of one or other structure, as we could then focus on the predicted outcomes of the appropriate model in evaluating the distribution of benefits of FDI between host and firm. Instead, we find often contradictory evidence as to how the competitions are conducted.

Some evidence in favour of an English auction can be found in the competition between US states to attract a Volkswagen (VW) production facility in 2007-8. Starting from an initial list of more than 100 potential sites, the candidates were gradually narrowed down to Alabama, Michigan, and Tennessee. In the end, Huntsville, Alabama and Chattanooga, Tennessee were the remaining sites in the competition, with Chattanooga being the ultimate winner. A bidding war was officially denied. ${ }^{4}$ While the dealing largely took place behind closed doors, there are indications of some degree of sequential bidding. For example, Tennessee was reported by the Birmingham News (2008) to "having upped its offer late in the bidding, according to published records" while Alabama's Governor is quoted in the Press Register (2008) as stating that there “comes a point in an auction where you don't want to be the one with your hand in the air." While not decisive, this case suggests that sequential bidding may play a role in the competition to attract FDI. Consequently, analysing how the equilibrium outcomes are affected by the structure of the bidding process seems a worthwhile endeavour.

If the equilibrium does not change with different protocols, the bidding structure of the contest can simply be ignored. But, should the timing of bids (simultaneous compared to

\footnotetext{
4 "Mr Wade (Alabama Economic Development Office) and Mr Farr (Tennessee Economic and Community Development Office) agreed that there was no bidding war between the states over incentives." Chattanooga Times Free Press (2008).
} 
sequential) affect the outcome of the game, then the bidding structure will have to be taken into account in the analysis of tax competition for FDI. We show that the firm cannot be harmed by moving from simultaneous offers to an English auction and that there are circumstances under which it may actually benefit. As there are no legal procedures that restrict the FDI search process to the use of sealed bids (unlike procurement rules in some jurisdictions), the firm may wish to encourage sequential offers in those situations from which it would gain.

From the national perspective, we show that, in many situations, inducing its rival to bid higher does not bring any benefits to a losing country. But it matters significantly if the losing country owns part of the firm, as its citizens capture part of the winner's bid. Thus the losing country has an incentive to raise its bid to induce the other country to follow suit. The greater the shares that its citizens own, the greater the benefit to the country from pushing up the bids. ${ }^{5}$

This pressure to overbid may be tempered if the country is unsure about its rival's valuation of the investment and, consequently, how large an offer it is prepared to make in order to secure the investment. We therefore extend the model to accommodate incomplete information with respect to national benefits from FDI.

\subsection{Related literature}

Tax competition among regions for attracting capital was first analyzed formally by Wilson (1986) and Zodrow and Mieszkowski (1986). ${ }^{6}$ Black and Hoyt (1989) analyze bidding competition for lumpy investment (or large firms), which has been followed by a now well established literature on international competition for FDI (e.g., Haaparanta, 1996; Haaland and Wooton, 1999; Haufler and Wooton, 1999; Fumagalli, 2003; Olsen and Osmundsen, 2003; Bjorvatn and Eckel, 2006; and Ferrett and Wooton, 2010).

Tax competition in the form of English auction has been considered in the literature (e.g.,

\footnotetext{
${ }^{5}$ As we shall show, the fact that the losing country has some ownership of the firm is all that matters for the English auction, not the size of the loser's share nor that the winning country owns any of the firm.

${ }^{6}$ See Wilson (1999), Wilson and Wildasin (2004), and Dembour (2008) for literature surveys of tax competition.
} 
by King, McAfee, and Welling, 1993) as an equivalent to the second-price auction. Black and Hoyt (1989) and King, McAfee, and Welling (1993) depart also from a complete-information framework and examine the bidding for a firm under incomplete information about the firm's local productivity. ${ }^{7}$ They demonstrate that the existence of uncertainty may cause overbidding beyond the expected welfare benefit that would be brought by a firm and its inefficient location. In their models, bidding regions do not know their own valuations of the FDI (or a region's geographical advantage over the other region) at the time of the bidding. In contrast to our model, regions would not bid beyond their individual valuations even if these were known when they bid for the firm. Beyond this, Bond and Samuelson (1986) show that, under incomplete information, tax holidays work as a signal for local productivity. ${ }^{8}$

We believe our paper to be the first to offer a detailed comparison of the outcomes of firstprice and English auctions for FDI, where the international distribution of firm ownership and uncertainty with respect to national gains from the FDI are both taken into account.

Kempf and Rota-Graziosi (2010), hereafter KRG, consider the outcome of tax competition for internationally mobile capital, examining the implications of allowing national bids to be made sequentially. They find that if governments endogenously determine the sequence of their bids the downward pressure on national bids (the so-called "race to the bottom") may be weakened and the familiar outcome that the larger country offers a higher tax rate than the smaller nation might be reversed. KRG's analysis is extended by Ogawa (2013) who shows that their results only hold when capital is owned by nonresidents, while domestic ownership of the footloose capital results in a reinstatement of the outcome of the simultaneous-bidding game. The model that KRG analyse is markedly different structure from that in the present paper. Their analysis is couched within the conventional tax competition framework where two national governments are bidding for the services of an homogeneous factor, where the equilibrium will be characterised by capital locating in both nations.

\footnotetext{
${ }^{7}$ See also Scoones and Wen (2001).

${ }^{8}$ Kaplan, Luski, and Wettstein (2003) extend Bond and Samuelson's (1986) model to allow regions to give grants to the firm in addition to lowering the tax rate.
} 
In contrast, our approach is rooted in another part of the literature on tax competition, where the governments bid to attract the production facility of a single firm. The winning nation gets the FDI while the loser gets nothing. Beyond this, KRG change the bidding protocol in such a way as to allow sequential bids, but still restrict each government to a single bid. In introducing the possibility of an English auction, we allow governments to make multiple bids, so that the number of bids is endogenous, not just the order of bidding. Like Ogawa, we examine the implications of the nationality of the owners of the capital. The competition in our model is to attract a specific firm whose shareholders may be resident in one or other of the two countries. This may reinforce the link between bids and ownership compared to the case of competition for homogeneous, footloose capital.

There is a related literature in finance that examines the impact of ownership on the outcome of an English auction (or second-price sealed bid auction). This is in the context of takeover battles where the bidders have shares (or "toeholds") in the target firm. ${ }^{9}$ Engelbrecht-Wiggans (1994), Burkart (1995), and Singh (1998) show that bidders are more aggressive in takeover contests when they have toeholds, and this may lead to inefficient outcomes in which the "winning" bidder loses from the acquisition of the firm. The analysis is generally set in an incomplete information environment in which bidders' valuations of the firm are unknown to each other. While we consider the case of asymmetric information, we assume initially that there is complete information which allows us to focus on the role ownership plays when bids are simultaneous and when they are sequential. We also examine situations where both bidders own shares in the firm while Burkart (1995), whose analysis is closest to ours, focuses on the case where only one bidder has a positive toehold when equilibrium properties are examined.

Our analysis is related to the theory of bidding with endogenous valuations [see, for example, Jehiel and Moldovanu (1996)]. Essentially our firm is selling a non-divisible "good" (the FDI) to one of two potential buyers. One of the countries, while unable to pay enough to attract the FDI, can make offers in order to reduce the negative externality of the firm

\footnotetext{
${ }^{9}$ When bidders have toeholds, the English auction and the second-price sealed-bid auction are equivalent if there are only two bidders. See Engelbrecht-Wiggans (1994) and Burkart (1995).
} 
investing in the rival nation. It does this by pushing up the equilibrium winning bid and thereby raising the after-tax profits of the firm, some of which are distributed to domestic shareholders.

\subsection{Outline of the paper}

The structure of the remainder of the paper is as follows. We outline a simple analytical model of international competition for FDI in section 2. In section 3, we revisit simultaneous bidding under complete information, setting it as our benchmark and confirming Ferrett and Wooton's (2010) invariance result that the winning bid equals the losing country's valuation of the FDI in the undominated Nash equilibrium, regardless of the international distribution of the firm's ownership. We show in Section 4 that this result is not robust to a change in the auction protocol. In an English auction, if the citizens of a losing country own any shares of the firm, the equilibrium winning bid equals the winner's valuation of the FDI. Thus a race to the bottom re-emerges despite the two countries having different valuations of the FDI. This arises whenever the losing country's citizens own shares of the firm giving it an incentive to push up its rival's bid and the ultimate pay-out to the firm.

We then investigate the role of information in bidding strategies and the resulting equilibrium bid. In section 5, we consider the situation where rival countries have incomplete information regarding each other's valuation of the FDI. When countries bid simultaneously, each nation's bid is smaller than its valuation of the FDI and the winning bid may be smaller or greater than the losing country's valuation. Each country's bid increases with its citizens' share of the firm. Thus Ferrett and Wooton's (2010) invariance result also fails in the presence of incomplete information. Of more consequence is the fact that partial ownership of the firm induces a country to bid more aggressively for the FDI, because its citizens re-capture their ownership share of the bid which reduces the cost of an excessively high offer. ${ }^{10}$ This reason for aggressive bidding contrasts sharply with that in the English auction, as both countries share an incentive to make higher bids when their citizens own part of the firm.

\footnotetext{
${ }^{10}$ It is easy to see that if its citizens own $100 \%$ of the firm, bidding for the FDI is virtually costless for the country.
} 
In section 6, we combine our innovations to derive the equilibrium of the English auction for FDI under incomplete information. We show that each country is prepared to bid more than its valuation if its citizens own a share of the firm. This may result in a race beyond the bottom, such that a country may lose by "winning" the auction. An inefficient allocation may also occur, in that the firm locates in the country with the lower valuation of the FDI. Section 7 investigates how the potential overbidding and misallocation of FDI affect agents' welfare and how these effects are related to the international distribution of the firm's ownership. Section 8 concludes the paper.

\section{The model}

There are two countries, $A$ and $B$, bidding to attract the investment of a single firm. The government of country $i(i=A, B)$ makes an offer of $b_{i}$ to the firm in order to attract its investment. When $b_{i}>0$ the country is prepared to subsidize the investment, while $b_{i}<0$ is a tax on the firm. We make the simplification that, in the absence of these transfers, the firm is indifferent between the two potential host locations as its profits are identical and equal to $\pi$ from producing in either country. ${ }^{11}$ After the governments make their bids, the firm decides where to locate its plant while the product markets in countries $A$ and $B$ are served in the final stage.

The benefit to country $i$ of having local investment is assumed to be $S_{i i}$, while it gets $S_{i j}$ $(i \neq j)$ when the firm produces in country $j$ and services its market through international trade. We assume that local investment is always preferred to imports and hence $S_{i} \equiv$ $S_{i i}-S_{i j}$, country $i$ 's valuation of the FDI, is always positive. ${ }^{12}$ We assume, without loss of generality, that $S_{A} \geq S_{B}>0$ in the case where countries' valuations are common knowledge.

\footnotetext{
${ }^{11}$ Thus there is no "geographical advantage" to the firm locating in one market relative to the other. We make this assumption simply to reduce the notational complexity. Our results would be qualitatively unchanged if, for example, pre-tax profits were higher in country $A$ (as is assumed by Ferrett and Wooton, $2010)$.

${ }^{12}$ This preference for local production can be attributed to a number of causes. In Haufler and Wooton (1999) it arises because locally produced goods are cheaper than imports from the other country. Among other justifications for the desire to attract FDI are the increased demand for domestic workers that it generates and the technological spillovers to indigenous industries from the increased the manufacturing activity.
} 
Thus country $A$ values the investment at least as much as country $B$ does. $^{13}$

In addition to the benefits of the FDI to the nation as a whole, country $i$ 's citizens are assumed to own a fraction $e_{i}$ of the investing firm and consequently receive that share of the firm's after-tax profits. We write $W_{i j}$ for country $i$ 's overall welfare benefit payoff from the firm locating in country $j$. Then, country $i$ 's welfare, dependent upon the location of the investment, is given by

$$
\begin{aligned}
& W_{i i}=e_{i}\left(\pi+b_{i}\right)-b_{i}+S_{i i}, \\
& W_{i j}=e_{i}\left(\pi+b_{j}\right)+S_{i j}, i \neq j .
\end{aligned}
$$

Let the net welfare benefit of hosting the firm be $W_{i} \equiv W_{i i}-W_{i j}$. Thus country $i$ strictly prefers hosting the firm if and only if

$$
W_{i}=e_{i}\left(b_{i}-b_{j}\right)-b_{i}+S_{i}>0,
$$

and is indifferent to the location of the FDI if $W_{i}=0$. As pre-tax profits are assumed to be the same for the firm regardless of where it locates, $b_{i}-b_{j}$ is the difference in the firm's net profits from choosing to invest in country $i$.

\section{Simultaneous bidding under complete information}

We start with a sealed-bid auction, identical to that of Ferrett and Wooton (2010), where the governments make their offers simultaneously and irreversibly. This yields a multiplicity of Nash equilibria. Ferrett and Wooton restrict their attention to outcomes where the countries do not make weakly dominated bids. Thus neither country ever makes a bid higher than its valuation of the investment. ${ }^{14}$ We shall, at least initially, not impose this limitation on the potential equilibria.

\footnotetext{
${ }^{13}$ In section 5, we introduce incomplete information, at which point each country will know its own valuation of the FDI but will only know the probability distribution of its rival's valuation.

${ }^{14}$ This rules out cases where a country would lose if it were to succeed in attracting the firm and makes a high offer only because it is certain that the firm will reject the overly generous subsidy in favour of a better deal being offered by the other country which values the investment more highly. Indeed, it can be shown that country $i$ 's offering at its own valuation $S_{i}$ weakly dominates any offer that is strictly higher than $S_{i}$.
} 
Given that pre-tax profits of the firm are the same in both potential host countries, country $A$ wins the auction only if

$$
b_{A} \geq b_{B}
$$

Country $A$ will surely win if it offers the firm a larger subsidy or lower tax than its rival, country $B$. Consider country $A$ 's best response to its rival's bid $b_{B}$. We show that country $A$ should offer:

$$
\begin{aligned}
& \text { (i) } b_{A}=-\pi \text { if } b_{B}<-\pi ; \\
& \text { (ii) } b_{A}=b_{B}+\varepsilon \text { if }-\pi \leq b_{B}<S_{A} ; \\
& \text { (iii) } b_{A} \in\left(-\infty, b_{B}\right] \text { if } b_{B}=S_{A} \text {; and } \\
& \text { (iv) } b_{A} \in\left(-\infty, b_{B}\right) \text { if } b_{B}>S_{A},
\end{aligned}
$$

where $\varepsilon>0$ is an arbitrarily small number. These bids are explained as follows.

(i) If country $B$ were to set tax greater than the firm's pre-tax profits, the firm would make a loss if it located in that country and would never invest there. All that country $A$ needs to do in order to attract the firm is to make an offer that would allow it at least to break even, that is $b_{A}+\pi \geq 0$. Thus, country $A$ 's optimal strategy is to set tax such that it fully extracts the firm's profits from the FDI.

(ii) Were country $B$ to offer a smaller tax (or grant a subsidy) to the firm such that it would makes an after-tax profit from its FDI, country $A$ would have to improve on its offer in order to win the auction. The winning bid is a tax/subsidy that gives the firm $\varepsilon$ more in after-tax profits than it would get from locating in country $B$.

(iii) There are limits to country A's generosity, however, as it will only be prepared to offer a subsidy up to its valuation of the FDI when it has a chance of winning the auction. If country $B$ were to offer a subsidy equal to country $A$ 's valuation such that $b_{B}=S_{A}$, country $A$ has two options. It can either try to attract the FDI by matching country $B$ 's bid. In such a case, it follows from (1) that $W_{A}=0$, meaning that country $A$ receives no benefit from the investment. Otherwise, country $A$ could make a lower bid that 
would ensure that it lost the auction. Thus, regardless of whether or not country $A$ wins the auction, it receives $W_{A B}$.

(iv) If country $B$ bids above country $A$ 's valuation of the investment, any bid that would beat country $B$ 's offer would result in $W_{A}<0$ and consequently country $A$ will ensure that it loses.

Country $B$ 's best response function is derived in an identical fashion.

If the two countries had identical valuations of the FDI, $S=S_{A}=S_{B}$, then each country would bid its valuation and the equilibrium bids would be identical, $b_{A}^{*}=b_{B}^{*}=S$. The firm would then be indifferent between locations and might invest in either country. The winning nation would be no better off than the loser, as all of the rent from the investment would be transferred to the firm in the subsidy. This is the familiar race to the bottom in taxes.

We assume, instead, that $S_{A}>S_{B}$. In this case there are multiple Nash equilibria, such that country $B$ offers a subsidy in the range $b_{B}^{*} \in\left[S_{B}, S_{A}\right]$ while country $A$ wins the auction by matching its rival's subsidy with $b_{A}^{*}=b_{B}^{*}$. It is easy to see that, given country $A$ wins the auction, neither country has an incentive to deviate from their prescribed strategies. Country $A$ 's equilibrium bid can be viewed as the limit strategy as $\varepsilon$ goes to zero. Country $A$ attracts the FDI at minimum cost, given its rival's bid, so has no incentive to deviate. Country $B$, on the other hand, wishes to lose the contest given country $A$ 's bid, and this is the outcome in equilibrium.

Ferrett and Wooton's (2010) result, that the international distribution of the firm's ownership is irrelevant to the outcome of the game, can be understood by considering the objective function of country $i$ given by (1). The citizens' ownership of the firm $e_{i}$ is multiplied by the difference in the two countries' bids; the citizens in country $i$ capture the fraction $e_{i}$ of their country's bid but lose the opportunity to capture the same fraction of the rival nation's bid. It might seem that this should influence the equilibrium offers and perhaps the location of the FDI. However, the bids made by the countries are such that the firm is only just persuaded to locate in one location over the other. Thus, in equilibrium, the bids are equal because the firm considers the two locations as being equally attractive. Consequently the first term 
in (1) is zero with domestic shareholders being unaffected by the equilibrium location of the FDI. Thus the distribution of ownership of the firm has no effect on the strength of national bids nor on the eventual locational choice of the firm in equilibrium.

Proposition 1 In the sealed-bid, first-price auction, there exist multiple Nash equilibria unless $S_{A}=S_{B}$. If $S_{A}>S_{B}$, country $A$ attracts the investment with a winning bid $b_{A}^{*} \in\left[S_{B}, S_{A}\right]$. If $S_{A}=S_{B}=S$, the location of the firm is indeterminate and the entire benefit of the investment is transferred to the firm through the equilibrium bids of $b_{A}^{*}=b_{B}^{*}=S$. Furthermore, the international distribution of the firm's ownership does not affect the countries' bidding strategies.

Let $S_{A}>S_{B}$. If country $B$ 's equilibrium bid is equal to its valuation of the FDI, that is $b_{B}^{*}=S_{B}$, then country $A$ will win the auction with the minimum subsidy by matching country $B$ 's subsidy. If $b_{B}^{*} \in\left(S_{B}, S_{A}\right)$, country $B$ 's equilibrium bid is strictly greater than $S_{B}$, its valuation of the FDI. Country $B$ can make such a bid because it "knows" that country $A$ will match the bid in order to win the auction.

Although this argument is important in understanding the equilibrium in later sections, one may argue that such Nash equilibria are not appealing. Indeed, any bid $b_{B}^{\prime}$ that is strictly greater than $S_{B}$ is dominated by $b_{B}=S_{B}$. We can demonstrate this by considering the best response of country $B$ to any bid $b_{A}$. (i) If $b_{A}<S_{B}$, then $b_{B}=S_{B}$ is strictly preferable to $b_{B}=b_{B}^{\prime}$ because country $B$ would still win the auction with less payment to the firm. (ii) If $S_{B} \leq b_{A}<b_{B}^{\prime}$, then $b_{B}=S_{B}$ is strictly preferable to $b_{B}=b_{B}^{\prime}$ because winning the auction in this case entails a loss for country $B$ as $e_{B}\left(b_{B}^{\prime}-b_{A}\right)-b_{B}^{\prime}+S_{B} \leq S_{B}-b_{A} \leq 0$. (iii) If $b_{A}=b_{B}^{\prime}$, then $b_{B}=S_{B}$ is preferable to $b_{B}=b_{B}^{\prime}$ should country $B$ win the auction while it would be indifferent between them when country $A$ wins. Finally, (iv) if country $A$ bids $b_{A}>b_{B}^{\prime}$, then country $B$ is indifferent between $b_{B}=S_{B}$ and $b_{B}=b_{B}^{\prime}$. Similarly, a bid by country $A$ 's that exceeds $S_{A}$ is dominated by $b_{A}=S_{A}$. Thus each country offers at most its valuation of the FDI in its undominated strategies. Consequently, the undominated Nash equilibrium, which is the Nash equilibrium with a pair of undominated strategies, is uniquely determined 
as $b_{A}^{*}=b_{B}^{*}=S_{B}$, with country $A$ winning the auction. ${ }^{15}$

Proposition 2 If $S_{A}>S_{B}$, there exists a unique undominated Nash equilibrium in which $b_{A}^{*}=b_{B}^{*}=S_{B}$ and the firm locates itself in country $A$. The winning bid is the minimum bid of all the Nash equilibrium bids.

\section{An English auction under complete information}

We now change the auction protocol to that of an English auction, in which each country has the opportunity to respond to the bid of its rival. As we discussed in the Introduction, this structure might be a better reflection of what has taken place in some cases of intergovernmental competition for FDI, where the investing firm has attempted to play potential host countries off against each other and thereby extract the highest offer. We want to determine how the equilibrium outcome of the competition is affected by the switch from simultaneous to sequential bids. We shall find that the ownership of the company will have an impact on the equilibrium bid, though the location of the FDI will be unchanged. Thus, the invariance result of Ferrett and Wooton (2010) is not robust to a change in the timing of bids. In particular, the ownership share of the "losing" nation will affect what the "winning" country has to pay to attract the FDI.

Following the initial bid of one country, its rival has the choice whether or not to make a higher offer to the firm. We assume that new bid is $\Delta>0$ above the existing standing bid. We continue to assume that pre-tax profits are the same in both locations for the firm, consequently the winner will be the country whose standing bid does not attract an improved bid from the other nation.

Country $i$ will certainly improve its bid as far as its net welfare benefit of hosting the firm is positive. That is, letting country $j$ 's standing bid be $b_{j}$, it follows from (1) that country $i$ will raise its bid to $b_{i}=b_{j}+\Delta$ if

$$
S_{i} \geq b_{j}+\left(1-e_{i}\right) \Delta .
$$

\footnotetext{
${ }^{15}$ The undominated Nash equilibrium is the outcome considered by Ferrett and Wooton (2010).
} 
Country $i$ will improve its bid as long as the additional cost (that part of the extra incentive that does not accrue to shareholders in country $i$ ) does not push the cost of the subsidy beyond the country's valuation of the FDI should it become the host nation. Country $i$ will not be worse off by bidding either as long as (2) holds should it lose the auction. Indeed, should country $i$ lose the auction, it has an incentive to bid even beyond its valuation $S_{i}$ if $e_{i}>0$.

If $S_{A}=S_{B} \equiv S$, neither country will raise its bid beyond $S$ in the subgame perfect Nash equilibrium (SPNE) because it would violate (2) for winning country $i$. Thus, in the limit equilibrium as $\Delta$ goes to zero, either country $A$ or $B$ wins the auction with its winning bid of $S$. That is, if the two countries value the FDI equally, the outcome is the same race to the bottom that arises in the simultaneous game, where the winning bid matches the nation's valuation of the investment. This result is independent of national ownership shares in the firm. Consequently, the outcome of tax competition between identical countries is independent of the timing of bids and the choice of an English auction or simultaneous sealed-bid auction is irrelevant to size of the equilibrium, winning bid.

The story will be very different, however, if countries have different valuations. When countries have different $S_{i}$, the nation with the higher valuation will attract the firm and this will be independent of which country makes the first bid. We now assume for the remainder of this section that country $A$ has a strictly higher valuation of the FDI than has country $B$, that is $S_{A}>S_{B}$, and derive the limit equilibrium of the SPNE of the bidding game.

We examine in the case where $S_{A}>S_{B}$ whether or not country $B$ has an incentive to raise its bid beyond its valuation when $b_{A} \in\left(S_{B}, S_{A}\right)$. Country $B$ knows that country $A$ will reply to its bid of $b_{B}=b_{A}+\Delta$ for a small $\Delta$ as long as (2) holds for $i=A$ with $b_{B}=b_{A}+\Delta$, that is whenever $b_{A}+\Delta+\left(1-e_{A}\right) \Delta \leq S_{A}$. Therefore, country $B$ can raise $A$ 's winning bid from $b_{A}$ to $b_{A}+2 \Delta$ if it offers $b_{A}+\Delta$ and make no bid in the succeeding round. In following this strategy, country $B$ gains $2 e_{B} \Delta$ relative to its having stopped bidding in the earlier round. Country $B$ continues to bid beyond its valuation and country $A$ counters the bid as long as $b_{A}<S_{A}$ when $\Delta$ is arbitrarily small. 
If citizens of country $B$ have no ownership shares in the firm $\left(e_{B}=0\right)$, there exist multiple SPNE whose outcomes are the same as in the case of the sealed-bid auction. Country A's winning bid must be at least $S_{B}$, otherwise country $B$ would continue to bid. Moreover, $B$ is indifferent to any $b_{A} \in\left[S_{B}, S_{A}\right]$ so long as it loses, since it gets $S_{B A}$ in any event. Country $B$ also knows that its bid will be countered if country $A$ 's bid is in this range. So the eventual loser can raise country $A$ 's winning bid to any level in this range. As with simultaneous bidding, however, the undominated SPNE outcome is that country $A$ wins the auction with its winning bid of $S_{B}$.

In contrast, if part of the firm is owned by the citizens of country $B$ (that is, $e_{B}>0$ ), the SPNE will be unique and characterized by country $A$ winning with a bid of $S_{A}$. This is because country $B$ knows that country $A$ will be prepared to raise its bid as long as $b_{A}<S_{A}$. Consequently country $B$ will bid beyond its own valuation of the FDI in order to force up the payment to the firm, as a share of this subsidy is paid to its own citizens. This result contrasts sharply with those in the previous literature, such as Haufler and Wooton (1999) as well as our benchmark case, in which the winning nation need only offer as much as the rival's valuation of the firm. Moreover, it is also different from the result of Ferrett and Wooton (2010) in that the firm's ownership structure affects the equilibrium outcome significantly.

Proposition 3 In an English auction under complete information when $S_{A}>S_{B}$, the subgame perfect equilibrium depends on the value of $e_{B}$. If $e_{B}=0$, the equilibrium outcomes are the same as in the case of sealed-bid first-price auction with multiple subgame perfect equilibria, although the undominated subgame-perfect equilibrium is uniquely determined with country $A$ 's winning bid of $S_{B}$. If $e_{B}>0$, there exists a unique subgame perfect equilibrium in which country $A$ wins the auction with its winning bid of $S_{A}$. If $S_{A}=S_{B}=S$, the location of the firm is indeterminate and the entire benefit of the investment is transferred to the firm through an equilibrium bid of $S$. 


\section{Simultaneous bidding under incomplete information}

Let us now examine the effect of incomplete information about countries' valuations of the FDI on the outcome of the simultaneous bidding. ${ }^{16}$ We assume that the benefits received both from attracting FDI and from importing are a country's private information. That is, $S_{i i}$ and $S_{i j}$ are known only to country $i$. However, we assume that the probability distribution of country $i$ 's valuation of the investment $S_{i}\left(\equiv S_{i i}-S_{i j}\right)$ is common knowledge. The bidding environment is an auction with independent private values; $S_{A}$ and $S_{B}$ are independently distributed according to the cumulative distribution function $F_{i}\left[S_{i}\right]$, for $i=A, B$, with a corresponding continuous density function of $f_{i}\left[S_{i}\right]$.

Let $\tilde{b}_{i}\left(S_{i}\right)$ denote the equilibrium bidding of country $i$ as a function of its valuation of the FDI. Country $A$, for example, wins the auction and obtain $e_{A}\left(\pi+b_{A}\right)-b_{A}+S_{A A}$ if $b_{A} \geq \tilde{b}_{B}\left(S_{B}\right)$, and loses the auction and obtain $e_{A}\left(\pi+\tilde{b}_{B}\left(S_{B}\right)\right)+S_{A B}$ otherwise. $^{17}$ Thus, country $A$ chooses $b_{A}$ to maximize

$\int_{S_{B} \leq \tilde{b}_{B}^{-1}\left(b_{A}\right)}\left[e_{A}\left(\pi+b_{A}\right)-b_{A}+S_{A A}\right] f_{B}\left[S_{B}\right] d S_{B}+\int_{S_{B}>\tilde{b}_{B}^{-1}\left(b_{A}\right)}\left[e_{A}\left(\pi+\tilde{b}_{B}\left(S_{B}\right)\right)+S_{A B}\right] f_{B}\left[S_{B}\right] d S_{B}$.

The first-order condition for this maximization problem can be written as

$$
\left(\tilde{b}_{B}^{-1}\right)^{\prime}\left(b_{A}\right) f_{B}\left[\tilde{b}_{B}^{-1}\left(b_{A}\right)\right]\left\{e_{A}\left[b_{A}-\tilde{b}_{B}\left(\tilde{b}_{B}^{-1}\left(b_{A}\right)\right)\right]-b_{A}+S_{A}\right\}=\left(1-e_{A}\right) F_{B}\left[\tilde{b}_{B}^{-1}\left(b_{A}\right)\right] .
$$

The left-hand side of (3) shows the expected benefit from raising the bid slightly from $b_{A}$. The chance of winning increases if $\tilde{b}_{B}\left(S_{B}\right)$ equals $b_{A}$, the probability density of whose event equals $\left(\tilde{b}_{B}^{-1}\right)^{\prime}\left(b_{A}\right) f_{B}\left[\tilde{b}_{B}^{-1}\left(b_{A}\right)\right]$. By winning the auction, country $A$ 's shareholders as a whole obtain $e_{A} b_{A}$ instead of $e_{A} \tilde{b}_{B}\left(\tilde{b}_{B}^{-1}\left(b_{A}\right)\right)$. This gain is obviously nil because increasing the bid slightly from $b_{A}$ would change the winner from $B$ to $A$ only when $b_{B}\left(S_{B}\right)$ is equal to $b_{A}$. Therefore, the net welfare gain from overturning the auction result equals $S_{A}-b_{A}$. The

\footnotetext{
${ }^{16}$ Panteghini and Schjelderup (2006) examine tax competition when the firm can choose the timing of the FDI in the presence of uncertainty on the value of the investment. Although introducing additional uncertainty is out of scope of the paper, we would be able to enrich the model in an interesting way if the value of the FDI and a country's valuation are positively correlated; if the bidding follows a sequential auction, the English (ascending-price) auction or Dutch (descending-price) auction, the firm continues to learn the value of FDI as the auction proceeds.

${ }^{17}$ Without loss of generality, we may assume that country $A$ wins the auction when the two countries' bids are equal.
} 
right-hand side of (3) shows, on the other hand, the expected loss from raising the bid. With probability $F_{B}\left[\tilde{b}_{B}^{-1}\left(b_{A}\right)\right]$, country $A$ wins the auction even without raising the bid. Thus, in such cases, country $A$ would lose the fraction $1-e_{A}$ of the increment of the bid by raising the bid unnecessarily.

We can solve (3) for $b_{A}$ to obtain country $A$ 's bidding function, which is implicitly defined by

$$
\tilde{b}_{A}\left(S_{A}\right)=S_{A}-\frac{\left(1-e_{A}\right) F_{B}\left[\tilde{b}_{B}^{-1}\left(\tilde{b}_{A}\left(S_{A}\right)\right)\right]}{\left(\tilde{b}_{B}^{-1}\right)^{\prime}\left(\tilde{b}_{A}\left(S_{A}\right)\right) f_{B}\left[\tilde{b}_{B}^{-1}\left(\tilde{b}_{A}\left(S_{A}\right)\right)\right]} .
$$

We find from (4) that $\tilde{b}_{A}\left(S_{A}\right)<S_{A}$ if $e_{A}<1$. Country $A$ 's bid approaches $S_{A}$ as $e_{A}$ increases to one. Similarly, we can readily obtain country $B$ 's bidding function as

$$
\tilde{b}_{B}\left(S_{B}\right)=S_{B}-\frac{\left(1-e_{B}\right) F_{A}\left[\tilde{b}_{A}^{-1}\left(\tilde{b}_{B}\left(S_{B}\right)\right)\right]}{\left(\tilde{b}_{A}^{-1}\right)^{\prime}\left(\tilde{b}_{B}\left(S_{B}\right)\right) f_{A}\left[\tilde{b}_{A}^{-1}\left(\tilde{b}_{B}\left(S_{B}\right)\right)\right]} .
$$

Proposition 4 In the presence of incomplete information regarding the other country's valuation of the FDI, each country's bid is smaller than its own valuation. The bid increases, however, with the share of the firm owned by its citizens.

Recall that if the countries' valuations are common knowledge, each country is willing to raise the bid up to its own valuation, but they both choose the bid equal to the smaller of the nations' valuations as their undominated strategies. Under incomplete information, neither country knows which has the lower valuation of the FDI. Therefore, they both make bids that are lower than their own valuations, in order to capture a positive net benefit should they win the auction. Their bids increase with their ownership shares of the firm, since their own citizens re-capture a part of their bids in proportion to their shares of the firm. Hence the effective costs of countries raising their bids are lower when they have larger ownership shares. If $e_{i}=1$, in particular, country $i$ 's effective costs of bidding equal zero, so that the equilibrium bid $\tilde{b}_{i}\left(S_{i}\right)$ matches its valuation of the FDI, $S_{i}$.

\section{An English auction under incomplete information}

Finally, we consider what might be the most relevant form of tax competition in practice: an English auction under incomplete information regarding countries' valuations of the FDI. 
As in the previous section, country $i$ 's valuation $S_{i}$ is private information although its probability distribution, characterized by a cumulative distribution function $F_{i}\left[S_{i}\right]$, is common knowledge.

Country $i$ 's strategy in the English auction for the FDI is characterized by its threshold of dropping out of the auction. Country $i$ will only counterbid if the expected payoff from raising the standing bid by $\Delta$ is not less than the guaranteed payoff from dropping out of the auction and letting its rival attract the FDI. This permits us to determine country $i$ 's threshold bid as $\bar{b}_{i}\left(S_{i}\right)$, the value of the standing bid at which the expected returns from staying in the auction and from dropping out are equalized. Thus, country $i$ will only stay in the auction, making a counterbid to country $j$ if the latter's last bid is below country $i$ 's threshold bid, that is $b_{j} \leq \bar{b}_{i}\left(S_{i}\right)$.

Country $A$, for example, counters the standing bid $b_{B}$ if the expected payoff from making a bid of $b_{A}=b_{B}+\Delta$ is greater than or equal to that from dropping out of the auction immediately. If country $A$ does make a new bid, there are two possible outcomes. First, it would win the auction if country $B$ does not to respond with its own counterbid. This would arise with probability

$$
\begin{aligned}
P_{B}\left(b_{B}+\Delta\right) & \equiv \operatorname{Prob}\left[b_{B}+\Delta>\bar{b}_{B}\left(S_{B}\right) \mid b_{B}-\Delta \leq \bar{b}_{B}\left(S_{B}\right)\right] \\
& =\frac{F_{B}\left[\bar{b}_{B}^{-1}\left(b_{B}+\Delta\right)\right]-F_{B}\left[\bar{b}_{B}^{-1}\left(b_{B}-\Delta\right)\right]}{1-F_{B}\left[\bar{b}_{B}^{-1}\left(b_{B}-\Delta\right)\right]}
\end{aligned}
$$

the probability that country $A$ 's bid $b_{A}=b_{B}+\Delta$ exceeds $B$ 's threshold bid $\bar{b}_{B}\left(S_{B}\right)$ conditional on the event that $S_{B}$ is large enough that $B$ has countered $A$ 's previous bid of $b_{B}-\Delta$, that is $b_{b}-\Delta \leq \bar{b}_{B}\left(S_{B}\right)$. The second outcome is where country $B$ does respond to country $A$ 's bid with a higher offer (after which country $A$ will have to decide once again whether to make a further bid), which would arise with probability $1-P_{B}\left(b_{B}+\Delta\right)$. Country $A$ calculates the expected payoff that it would receive from making a new bid and compares this to the guaranteed payoff from dropping out of the auction without further bidding.

Country $A$ 's expected payoff from making a new bid when the standing bid is $b_{B}$, which is denoted by $C\left(b_{B}\right)$, is at least as large as the expected payoff from making a new bid and dropping out of the auction in its next turn if the new bid is countered by $B$. Country $A$ 
will certainly stay in the auction and make a new bid if this specific bidding strategy gives country $A$ a higher payoff than dropping out of the auction immediately. Thus, we have the following sequence of the inequalities:

$$
\begin{aligned}
& C\left(b_{B}\right) \\
& \geq\left[e_{A}\left(\pi+b_{B}+\Delta\right)-\left(b_{B}+\Delta\right)+S_{A A}\right] P_{B}\left(b_{B}+\Delta\right)+\left[e_{A}\left(\pi+b_{B}+2 \Delta\right)+S_{A B}\right]\left[1-P_{B}\left(b_{B}+\Delta\right)\right] \\
& \geq e_{A}\left(\pi+b_{B}\right)+S_{A B} .
\end{aligned}
$$

If $P_{B}\left(b_{B}+\Delta\right)=0$, the first term of the middle expression in (7) is zero and country $B$ will definitely continue to bid. In this case, it is certainly worthwhile for country $A$ to make a further bid, even if it eventually loses the auction, as the payment made to citizens owning some shares of the firm is driven up. If, at the other extreme, $P_{B}\left(b_{B}+\Delta\right)=1$ and country $A$ 's next bid would certainly win the auction, the decision as to whether to make a further bid depends upon country $A$ 's valuation of the FDI relative to the cost of attracting it, that is whether $S_{A}$ exceeds $b_{B}+\left(1-e_{A}\right) \Delta$. This argument is made more transparent if we rewrite the second inequality of (7) by subtracting the right-hand side from the left-hand side as

$$
\left[S_{A}-b_{B}-\left(1-e_{A}\right) \Delta\right] P_{B}\left(b_{B}+\Delta\right)+2 e_{A} \Delta\left[1-P_{B}\left(b_{B}+\Delta\right)\right] \geq 0
$$

Substituting (6) into (8), we obtain a new sufficient condition for country $A$ to be prepared to make a further bid

$$
\frac{\left[S_{A}-b_{B}-\left(1-e_{A}\right) \Delta\right]}{1-F_{B}\left[\bar{b}_{B}^{-1}\left(b_{B}-\Delta\right)\right]} \frac{F_{B}\left[\bar{b}_{B}^{-1}\left(b_{B}+\Delta\right)\right]-F_{B}\left[\bar{b}_{B}^{-1}\left(b_{B}-\Delta\right)\right]}{2 \Delta}+e_{A} \frac{1-F_{B}\left[\bar{b}_{B}^{-1}\left(b_{B}+\Delta\right)\right]}{1-F_{B}\left[\bar{b}_{B}^{-1}\left(b_{B}-\Delta\right)\right]} \geq 0 .
$$

Once again, we let $\Delta \rightarrow 0$ to obtain

$$
\left(S_{A}-b_{B}\right) \frac{f_{B}\left[\bar{b}_{B}^{-1}\left(b_{B}\right)\right] \bar{b}_{B}^{-1 \prime}\left(b_{B}\right)}{1-F_{B}\left[\bar{b}_{B}^{-1}\left(b_{B}\right)\right]}+e_{A} \geq 0,
$$

where $\bar{b}_{i}^{-1 \prime}\left(b_{i}\right)=d \bar{b}_{i}^{-1}\left(b_{i}\right) / d b_{i}>0$. This can be rewritten as

$$
b_{B} \leq S_{A}+\frac{\bar{b}_{B}^{\prime}\left(\bar{b}_{B}^{-1}\left(b_{B}\right)\right)\left\{1-F_{B}\left[\bar{b}_{B}^{-1}\left(b_{B}\right)\right]\right\}}{f_{B}\left[\bar{b}_{B}^{-1}\left(b_{B}\right)\right]} e_{A},
$$

where we have used $\bar{b}_{B}^{-1 \prime}\left(b_{B}\right)=1 / \bar{b}_{B}^{\prime}\left(\bar{b}_{B}^{-1}\left(b_{B}\right)\right)$. Thus country $A$ would be prepared to make a further bid if (9) is satisfied. 
The threshold bid for country $A, \bar{b}_{A}\left(S_{A}\right)$, is determined implicitly as $b_{B}$ that satisfies (9) with equality. This is because when country $A$ is indifferent between making a new bid and dropping out of the auction, $C\left(b_{B}\right)=e_{A}\left(\pi+b_{B}\right)+S_{A B}$ should hold in (7), and hence all weak inequalities in (7) and (8) hold with equality. Consequently, country $A$ 's threshold bid can be written as

$$
\bar{b}_{A}\left(S_{A}\right)=S_{A}+\frac{\bar{b}_{B}^{\prime}\left(\bar{b}_{B}^{-1}\left(\bar{b}_{A}\left(S_{A}\right)\right)\right)\left\{1-F_{B}\left[\bar{b}_{B}^{-1}\left(\bar{b}_{A}\left(S_{A}\right)\right)\right]\right\}}{f_{B}\left[\bar{b}_{B}^{-1}\left(\bar{b}_{A}\left(S_{A}\right)\right)\right]} e_{A} .
$$

Similarly, we obtain country $B$ 's threshold bid as

$$
\bar{b}_{B}\left(S_{B}\right)=S_{B}+\frac{\bar{b}_{A}^{\prime}\left(\bar{b}_{A}^{-1}\left(\bar{b}_{B}\left(S_{B}\right)\right)\right)\left\{1-F_{A}\left[\bar{b}_{A}^{-1}\left(\bar{b}_{B}\left(S_{B}\right)\right)\right]\right\}}{f_{A}\left[\bar{b}_{A}^{-1}\left(\bar{b}_{B}\left(S_{B}\right)\right)\right]} e_{B} .
$$

Observe in (10) and (11) that if $e_{i}=0$, then $\bar{b}_{i}\left(S_{i}\right)=S_{i}$. Country $i$ has no incentive to bid above its valuation $S_{i}$ in order to push up the rival country's bid, and thereby risk "winning" the auction, as none of this will benefit citizens in country $i$. If on the other hand $e_{i}>0$, country $i$ is willing to risk trying to raise the winning bid, hoping that its rival eventually wins the auction. The threshold bid balances the cost of potentially winning the auction with a bid above the country's valuation and the benefits of an increase in the payout to shareholders should the country lose the auction.

Proposition 5 In an English auction under incomplete information, if $e_{i}=0$ then each country $i$ continues to bid until the standing bid reaches its own valuation of the firm $S_{i}$, otherwise when $e_{i}>0$ it bids beyond its valuation. The higher is $e_{i}$, the higher is the threshold bid. As a consequence, a country that has some ownership of the firm may lose by winning the auction.

\section{An example}

To gain more insights of the result, let us specify the probability distribution as the exponential distribution with the support $\left[a_{i}, \infty\right)$ for $a_{i} \geq 0$, i.e.,

$$
\begin{aligned}
F_{i}\left[S_{i}\right] & =1-\exp \left[-\lambda_{i}\left(S_{i}-a_{i}\right)\right] \\
f_{i}\left[S_{i}\right] & =\lambda_{i} \exp \left[-\lambda_{i}\left(S_{i}-a_{i}\right)\right] .
\end{aligned}
$$


This probability distribution has a mean of $a_{i}+1 / \lambda_{i}$ and a variance of $1 / \lambda_{i}^{2}$. Moreover, we have for $i=A, B$

$$
\frac{1-F_{i}\left[\bar{b}_{i}^{-1}\left(b_{j}\right)\right]}{f_{i}\left[\bar{b}_{i}^{-1}\left(b_{j}\right)\right]}=\frac{1}{\lambda_{i}}
$$

for any $b_{i}$. Thus, threshold bids expressed in (10) and (11) can be rewritten as

$$
\begin{aligned}
& \bar{b}_{A}\left(S_{A}\right)=S_{A}+\frac{e_{A}}{\lambda_{B}}, \\
& \bar{b}_{B}\left(S_{B}\right)=S_{B}+\frac{e_{B}}{\lambda_{A}} .
\end{aligned}
$$

The larger the share of the firm held by a country, the greater its willingness to continue in the auction, in order to push up the expected redistribution of after-tax profits to its own citizens. Moreover, the higher the mean (and hence the variance) of the rival country's valuation, the greater its willingness to continue the auction, since the risk of winning the auction is smaller when it raises the bid at any stage of the auction.

To further examine the properties of the equilibrium, let us look at several specific cases.

1. $S_{A}>S_{B}$ and $e_{A}=e_{B}=0$.

Country $A$ wins with the winning bid of $S_{B}$. The outcome is the same as those in both simultaneous bidding under complete information and the undominated subgame perfect equilibrium outcome when $e_{B}=0$ in an English auction under complete information. It is worthwhile to note that, in the English auction, making the information about countries' valuations private (as opposed to public) eliminates all of the subgameperfect equilibria with winning bids by country $A$ higher than its evaluation $S_{A}$. This is because, when the information is incomplete, country $B$ is no longer confident that country $A$ would match $B$ 's bid beyond $S_{B}$.

2. $S_{A}>S_{B}$ and $e_{A} / \lambda_{B}=e_{B} / \lambda_{A}>0$.

Country $A$ wins with the winning bid of $S_{B}+\left(e_{B} / \lambda_{A}\right)$. The winning bid may exceed country $A$ 's valuation $S_{A}$ if $e_{B}$ is large or $\lambda_{A}$ is small; country $B$ 's threshold bid is high if country $B$ has a large incentive to raise the rival country's winning bid (i.e., $e_{B}$ is large) or if the risk of country $B$ 's winning with a bid beyond $S_{B}$ is small (i.e., $\lambda_{A}$ is 
small). Note also that this outcome is more likely to occur if $e_{A}$ is large or $\lambda_{B}$ is small so that country $A$ 's threshold bid is more likely to exceed that of country $B .^{18}$

3. $S_{A}=S_{B}$ and $e_{A} / \lambda_{B}=e_{B} / \lambda_{A}>0$.

Either country $A$ or country $B$ wins the auction with the winning bid of $S_{A}+\left(e_{A} / \lambda\right)=$ $S_{B}+\left(e_{B} / \lambda\right)$, which certainly exceeds the winner's valuation of the FDI. The two countries race beyond the bottom if they are symmetric.

4. $S_{A}>S_{B}$ and $S_{A}+\left(e_{A} / \lambda_{B}\right)<S_{B}+\left(e_{B} / \lambda_{A}\right)$.

Country $B$ wins the auction even though country $A$ 's valuation of the FDI is higher than that of country $B$. The resulting location of the firm is inefficient, and country $B$ certainly loses by winning the auction.

We summarize some of the above findings in the following proposition.

Proposition 6 In an English auction under incomplete information, a country may lose by winning the auction. This race beyond the bottom is more likely to occur if $e_{A}$ and $e_{B}$ are large and $\lambda_{A}$ and $\lambda_{B}$ are small so that the countries' threshold bids are large. The country with a lower valuation of the FDI than the other may win the auction if its citizens hold a large share of the firm or if the mean of the other country's valuation of the FDI is large.

\section{Welfare comparisons}

In this section, we compare the allocation efficiency and each party's welfare between the two auction protocols of simultaneous bidding and the English auction. In order to simplify the exposition, we assume here that $e_{i}>0$ for $i=A, B$ and $e_{A}+e_{B}<1$.

We begin with the welfare comparison under complete information, maintaining our assumption that $S_{A}>S_{B}$. As we have shown in sections 3 and 4 , country $A$, as the country with the higher valuation, always wins in this case. and consequently the FDI is efficiently allocated. The firm's revenue from the bidding equals $S_{B}$ in the undominated Nash

\footnotetext{
${ }^{18}$ In this example, $e_{A} / \lambda_{B}=e_{B} / \lambda_{A}$.
} 
equilibrium in the case of the simultaneous bidding and $S_{A}$ in the case of an English auction. The firm unambiguously prefers an English auction to simultaneous bidding, as does the losing country $B$ which reaps a higher benefit for its domestic shrareholders. Country $A$, on the other hand, prefers simultaneous bidding. Aggressive bidding in an English auction therefore benefits both the firm and the losing country but harms the winner.

We now turn to the case of incomplete information. We consider the case in which the probability distributions of the valuations are the same between the two countries, assuming that $S_{i j}=0$ for $i \neq j$ for simplicity. Without loss of generality, we assume that $e_{A} \geq e_{B}$. In order to derive concrete results and obtain some useful insights, we further assume that both $S_{A}$ and $S_{B}$ are uniformly distributed on $[0,1] .{ }^{19}$ It follows from (4) and (5) that the countries' bidding functions can be written as follows in the case of the simultaneous bidding:

$$
\tilde{b}_{A}\left(S_{A}\right)=\frac{S_{A}}{2-e_{A}},:: \tilde{b}_{B}\left(S_{B}\right)=\frac{S_{B}}{2-e_{B}} .
$$

Similarly, we obtain the bidding functions in the case of an English auction from (10) and (11):

$$
\bar{b}_{A}\left(S_{A}\right)=\frac{S_{A}+e_{A}}{1+e_{A}},:: \bar{b}_{B}\left(S_{B}\right)=\frac{S_{B}+e_{B}}{1+e_{B}} .
$$

We can easily confirm that country $i$ 's bid rises as $e_{i}$ increases in both auction protocols.

For the FDI to be efficiently allocated, country $A$ should win if and only if $S_{A}>S_{B}$. But when $e_{A}$ and $e_{B}$ are positive, this may not happen. If $e_{A}=e_{B}$, country $A$ wins if and only if $S_{A}>S_{B}$ as we see from (12) and (13) in both protocols. Even if the presence of the shareholding affects both countries' bidding incentives, it affects symmetrically between the countries so that no distortion in the outcome would arise. If $e_{A}>e_{B}$, on the other hand, country $A$ may win the auction even though $S_{A}<S_{B}$ if $S_{A}$ and $S_{B}$ happen to be close.

To see which bidding protocol achieves a higher ex ante efficiency, we calculate the expected efficiency losses caused by misallocation of the FDI and compare them in the two bidding protocols. In the case of simultaneous bidding, country $A$ wins the auction when efficiency requires country $B$ to win if and only if $\left(2-e_{A}\right) S_{B} /\left(2-e_{B}\right)<S_{A}<S_{B}$. Thus,

\footnotetext{
${ }^{19}$ Unlike the exponential distribution function considered in the previous section, the uniform distribution allows us to explicitly derive the bidding functions in both auction protocols.
} 
we can write the expected efficiency loss as

$$
\int_{0}^{1} \int_{\frac{\left(2-e_{A}\right) S_{B}}{2-e_{B}}}^{S_{B}}\left(S_{B}-S_{A}\right) d S_{A} d S_{B}=\frac{\left(e_{A}-e_{B}\right)^{2}}{6\left(2-e_{B}\right)^{2}} .
$$

Similarly, country $A$ wins the auction when efficiency requires country $B$ to win if and only if $S_{A}<S_{B}<\left[\left(1+e_{B}\right) S_{A}+e_{A}-e_{B}\right] /\left(1+e_{A}\right)$ in the case of an English auction. Thus, we can write the expected efficiency loss as

$$
\int_{0}^{1} \int_{S_{A}}^{\frac{S_{A}\left(1+e_{B}\right)+e_{A}-e_{B}}{1+e_{A}}}\left(S_{B}-S_{A}\right) d S_{B} d S_{A}=\frac{\left(e_{A}-e_{B}\right)^{2}}{6\left(1+e_{A}\right)^{2}}
$$

Note that the efficiency loss is zero if $e_{A}=e_{B}$ in both protocols. It is also straightforward from (14), (15), and $2-e_{B}>1+e_{A}$ (which is equivalent to $e_{A}+e_{B}<1$ ) that the efficiency loss is smaller in the case of simultaneous bidding than in an English auction.

Whether the firm's expected revenue is higher in an English auction than with simultaneous bidding depends on the levels of $e_{A}$ and $e_{B}$. The firm's expected revenue equals

$$
\begin{aligned}
E \tilde{R} & =\int_{0}^{1}\left[\int_{0}^{\frac{S_{B}\left(2-e_{A}\right)}{2-e_{B}}} \tilde{b}_{B}\left(S_{B}\right) d S_{A}+\int_{\frac{S_{B}\left(2-e_{A}\right)}{2-e_{B}}}^{1} \tilde{b}_{A}\left(S_{A}\right) d S_{A}\right] d S_{B} \\
& =\frac{1}{2\left(2-e_{A}\right)}+\frac{2-e_{A}}{6\left(2-e_{B}\right)^{2}}
\end{aligned}
$$

in the simultaneous bidding and

$$
\begin{aligned}
E \bar{R} & =\int_{0}^{1}\left[\int_{0}^{\frac{S_{A}\left(1+e_{B}\right)+e_{A}-e_{B}}{1+e_{A}}} \bar{b}_{B}\left(S_{B}\right) d S_{B}+\int_{\frac{S_{A}\left(1+e_{B}\right)+e_{A}-e_{B}}{1+e_{A}}}^{1} \bar{b}_{A}\left(S_{A}\right) d S_{B}\right] d S_{A} \\
& =\frac{1+2 e_{B}}{2\left(1+e_{B}\right)}-\frac{1+e_{B}}{6\left(1+e_{A}\right)^{2}}
\end{aligned}
$$

in the English auction. Figure 1 shows the regions of $\left(e_{A}, e_{B}\right)$ (with the restriction of $e_{A}+e_{B}<$ 1 and $\left.e_{A}>e_{B}\right)$ in which the firm's expected revenue is higher in one protocol than the other. As the figure indicates, the firm benefits from aggressive bidding in an English auction in most cases. But the firm's expected revenue is higher with simultaneous bidding if $e_{A}$ is very large and $e_{B}$ is very small. In this region, country $A$ is likely to win the auction because $e_{A}$ is so much greater than $e_{B}$. Since the winning country pays the losing country's bid, however, the revenue when country $A$ wins is not large for small $e_{B}$. 
Now, let us compare country $A$ 's expected welfare between the two protocols. Country $A$ 's welfare equals

$E \tilde{W}_{A}=\int_{0}^{1}\left\{\int_{0}^{\frac{S_{B}\left(2-e_{A}\right)}{2-e_{B}}} e_{A}\left(\pi+\tilde{b}_{B}\left(S_{B}\right)\right) d S_{A}+\int_{\frac{S_{B}\left(2-e_{A}\right)}{2-e_{B}}}^{1}\left[e_{A}\left(\pi+\tilde{b}_{A}\left(S_{A}\right)\right)-\tilde{b}_{A}\left(S_{A}\right)+S_{A}\right] d S_{A}\right\} d S_{B}$

in the simultaneous bidding and

$$
\begin{aligned}
E \bar{W}_{A}= & \int_{0}^{1}\left\{\int_{0}^{\frac{S_{A}\left(1+e_{B}\right)+e_{A}-e_{B}}{1+e_{A}}}\left[e_{A}\left(\pi+\bar{b}_{B}\left(S_{B}\right)\right)-\bar{b}_{B}\left(S_{B}\right)+S_{A}\right] d S_{B}\right. \\
& \left.+\int_{\frac{S_{A}\left(1+e_{B}\right)+e_{A}-e_{B}}{1+e_{A}}}^{1} e_{A}\left(\pi+\bar{b}_{A}\left(S_{A}\right)\right) d S_{B}\right\} d S_{A}
\end{aligned}
$$

in an English auction. Figure 2 shows the regions of $\left(e_{A}, e_{B}\right)$ in which country $A$ 's expected welfare is higher in one protocol than the other. As the figure shows, country $A$ prefers simultaneous bidding if $e_{A}$ and $e_{B}$ are close. In such cases, country $A$ 's chance of winning is not much greater than that of country $B$. Since the efficiency loss and the firm's expected revenue are both smaller in simultaneous bidding in this region, the joint surplus of the two countries is greater. That is why country $A$ prefers the simultaneous bidding when $e_{A}$ is not much bigger than $e_{B}$. If, however, $e_{A}$ is large and $e_{B}$ is small, country $A$ prefers an English auction. The greater is $e_{A}$, the more country $A$ benefits when it loses. Moreover, the smaller is $e_{B}$, the more country $A$ benefits when it wins, because it makes a smaller payment to the firm (country $B$ 's bid). This explains why country $A$ prefers an English auction if $e_{A}$ is sufficiently larger than $e_{B}$.

The expected welfare of country $B$ can be written similarly to (16) and (17) and is therefore omitted. It can be shown that country $B$, as the country that has a smaller ownership share of the firm, always prefers simultaneous bidding to an English auction. If $e_{B}$ is not much smaller than $e_{A}$, then country $B$ prefers simultaneous bidding for the same reason that country $A$ does. If $e_{B}$ is sufficiently smaller than $e_{A}$, country $B$ also prefers simultaneous bidding for the exactly the opposite reason as to why country $A$ prefers an English auction.

The following proposition summarizes our findings for this specific example. 
Proposition 7 Suppose that $S_{A}$ and $S_{B}$ are stochastic and each is independently and uniformly distributed on $[0,1]$. Then, the expected efficiency loss is greater in an English auction than with simultaneous bidding. Nevertheless, the firm prefers an English auction in most cases except when $e_{A}$ is sufficiently greater than $e_{B}$. Country $A$, as the country that has a higher share of the firm, also prefers an English auction in most cases except when $e_{A}$ is only slightly larger than $e_{B}$. Country $B$, on the other hand, always prefers simultaneous bidding.

Having shown that aggressive bidding in the English auction generally reduces the joint surplus of potential host countries of the FDI, we can discuss what these countries can do to avoid harmful tax competition. ${ }^{20}$ When overbidding is serious, as in the case where $e_{A}$ and $e_{B}$ are large, bidding countries have a strong incentive to mitigate the competition. Some sort of coordination is possible especially if the countries belong to the same economic region, such as the EU, or if the bidding parties are regional governments of a country. ${ }^{21}$ Indeed, the European Commission, for example, urges member states to refrain from harmful tax competition. Supranational authorities or federal governments may also be able to coordinate bidding to prevent potential hosts of the FDI from bidding sequentially. Financial constraints that face the bidding parties can also mitigate tax competition. Recent financial crisis may have such unintended consequences.

\section{Conclusion}

This paper has investigated countries' bidding strategies for a firm and the resulting equilibrium bids across a wider range of bidding environments than are traditionally examined. In a world of complete information and when the firm is truly "foreign" (that is, owned entirely by citizens of other countries), an English auction yields the same outcome, with respect to the equilibrium bid and the location of the FDI, as that of the familiar, simultaneous,

\footnotetext{
${ }^{20}$ Fumagalli (2003) emphasizes a positive aspect of tax competition by showing that tax competition facilitates firm's efficiency-enhancing location decisions.

${ }^{21}$ Kessing et al. (2009) point out that vertical fiscal inefficiency in federalism entails reduced incentive to attract FDIs, which offers another reason why regional governments of a country may be able to refrain from entering harmful tax competition.
} 
sealed-bid auction. As a result, the choice of auction protocol is irrelevant to the outcome of the competition.

If, however, citizens of bidding countries own shares of the firm, the outcomes differ. The equilibrium winning bid is greater in an English auction than in simultaneous bidding. Thus, the pressures for a "race to the bottom" in taxes are stronger when countries have the opportunity to respond to bids than in the case of simultaneous sealed-bid auctions. This creates a motive for firms to encourage potential host nations to respond to bids offered by their rivals. Asymmetry of information on countries' valuations of the firm's investment naturally adds ex ante uncertainty about the winner's identity and the winning bid, as well as generating the potential for ex post inefficiency of the firm's location. As a result, it is possible that the location of the FDI will be inefficient.

Elements of our results appear in the finance literature on takeovers of firms, such as Burkart (1995). As far as we are aware, we have provided the first application to international tax competition to attract a firm's FDI. Moreover, we have disentangled the roles played by national ownership shares and incomplete information in yielding different outcomes from simultaneous-bidding contests and English auctions.

How relevant are our results? We have found some evidence from the USA that investing firms try to encourage states to improve on existing bids by their rivals, suggesting that the bidding structure may in some cases be closer to the sequential nature of an English auction than that of the sealed-bid, first-price auction. Our analysis has shown that, when the bidding states have ownership shares in the firm, the manner in which the auction is conducted is of critical importance for its outcome. With respect to the VW example discussed in the introduction, one could reasonably argue that the citizens of Alabama and Tennessee are unlikely to have significant shareholdings in the German firm and, consequently, the differences in outcomes are unlikely to be important. But that does not mean ownership will never play a role. Suppose that a similar competition were to take place for a new VW production facility, but this time in Europe. VW is predominantly a German company including a sig- 
nificant degree of state ownership. ${ }^{22}$ Our analysis suggests that this could play a significant role in determining the winning bids for any new European production facilities.

\section{References}

[1] Bjorvatn, Kjetil and Carsten Eckel (2006), "Policy Competition for Foreign Direct Investment between Asymmetric Countries," European Economic Review, 50, 1891-1907. Black, Dan A. and William H. Hoyt (1989), "Bidding for Firms," American Economic Review, 79, 1249-1256.

Bond, Eric W. and Larry Samuelson (1986), "Tax Holidays as Signals," American Economic Review, 76, 820-826.

Burkart, Mike (1995), "Initial Shareholdings and Overbidding in Takeover Contests," Journal of Finance, 50, 1491-1515.

Chattanooga Times Free Press, 16 July 2008, Chattanooga, TN. www.timesfreepress.com/news/2008/jul/16/chattanooga-vw-incentives-could-top400-million-ov/

Davies, Ronald B. (2005), "State Tax Competition for Foreign Direct Investment: A Winnable War?" Journal of International Economics, 67, 498-512.

Dembour, C. (2008), "Competition for Business Location: A Survey," Journal of Industry, Competition and Trade, 8, 89-111.

Devereux, Michael P., Ben Lockwood, and Michela Redoano (2008), "Do Countries Compete over Corporate Tax Rates?" Journal of Public Economics, 92, 1210-1235.

Engelbrecht-Wiggans, Richard (1994), "Auctions with Price-Proportional Benefits to Bidders, Games and Economic Behavior, 6, 339-346.

\footnotetext{
${ }^{22}$ Volkswagen's headquarters and a major production facility are located in Wolfsburg, Lower Saxony. The state of Lower Saxony owns a 12.9\% share of the company (as of 31 December 2010)
} 
Ferrett, Ben and Ian Wooton (2010), "Tax Competition and the International Distribution of Ownership: An Invariance Result," International Tax and Public Finance, 17, 518-531.

Financial Post, 3 August 1985.

Fumagalli, Chiara (2003), "On the Welfare Effects of Competition for Foreign Direct Investment," European Economic Review, 47, 963-983.

Greenstone, Michael and Enrico Moretti (2004), "Bidding for Industrial Plants: Does Winning a 'Million Dollar Plant' Increase Welfare?” NBER Working Paper 9844.

Haaland, Jan I. and Ian Wooton (1999), "International Competition for Multinational Investment," Scandinavian Journal of Economics, 101, 631-650.

Haaparanta, Pertti (1996), "Competition for Foreign Direct Investments," Journal of Public Economics, 63, 141-153.

Haufler, Andreas and Ian Wooton (1999), "Country Size and Tax Competition for Foreign Direct Investment," Journal of Public Economics, 71, 121-139.

Jehiel, Philippe, and Benny Moldovanu (1996), "Strategic Nonparticipation," Rand Journal of Economics, 27, 84-98.

Kaplan, Todd, Israel Luski and David Wettstein (2003), "Government Policy towards Multi-National Corporations," Economic Bulletin, 6, 1-8.

Kempf, Hubert, and Grégoire Rota-Graziosi (2010), "Endogenizing Leadership in Tax Competition," Journal of Public Economics, 94, 768-776.

Kessing, Sebastian G., Kai A. Konrad and Christos Kotsogiannis (2009), "Federalism, Weak Institutions and the Competition for Foreign Direct Investment," International Tax and Public Finance, 16, 105-123.

King, Ian, R., Preston McAfee and Linda Welling (1993), "Industrial Blackmail: Dynamic Tax Competition and Public Investment," Canadian Journal of Economics, 26, 590-608. 
New York Times, October 18, 2002.

Ogawa, Hikaru (2013), "Further Analysis on Leadership in Tax Competition: The Role of Capital Ownership," International Tax and Public Finance, 20, 474-484.

Olsen, Trond E. and Petter Osmundsen (2003), "Spillovers and International Competition for Investments," Journal of International Economics, 59, 211-238.

Panteghini, Paolo M., and Guttorm Schjelderup (2006), "To Invest or Not to Invest: A Real Options Approach to FDIs and Tax Competition," International Tax and Public Finance, 13, 643-660.

Press Register, 16 July 2008, Mobile, AL. www.al.com/news/pressregister/index.ssf?/base/news/1216262708120070.xml\&coll=3

Scoones, David and Jean-François Wen (2001), "Common and Private Values of the Firm in Tax Competition," Journal of Public Economic Theory, 3, 373-389.

Singh, Rajdeep (1998), "Takeover Bidding with Toeholds: The Case of the Owner's Curse," Review of Financial Studies, 11, 679-704.

Wilson, John Douglas (1986), "A Theory of Interregional Tax Competition," Journal of Urban Economics, 19, 296-315.

Wilson, John Douglas (1999), "Theories of Tax Competition," National Tax Journal, $52,269-304$.

Wilson, John Douglas and David E. Wildasin (2004), "Capital Tax Competition: Bane or Boon?" Journal of Public Economics, 88, 1065-1091.

Zodrow, George R. and Peter Mieszkowski (1986), "Pigou, Tiebout, Property Taxation, and the Underprovision of Local Public Goods," Journal of Urban Economics, 19, 356370. 


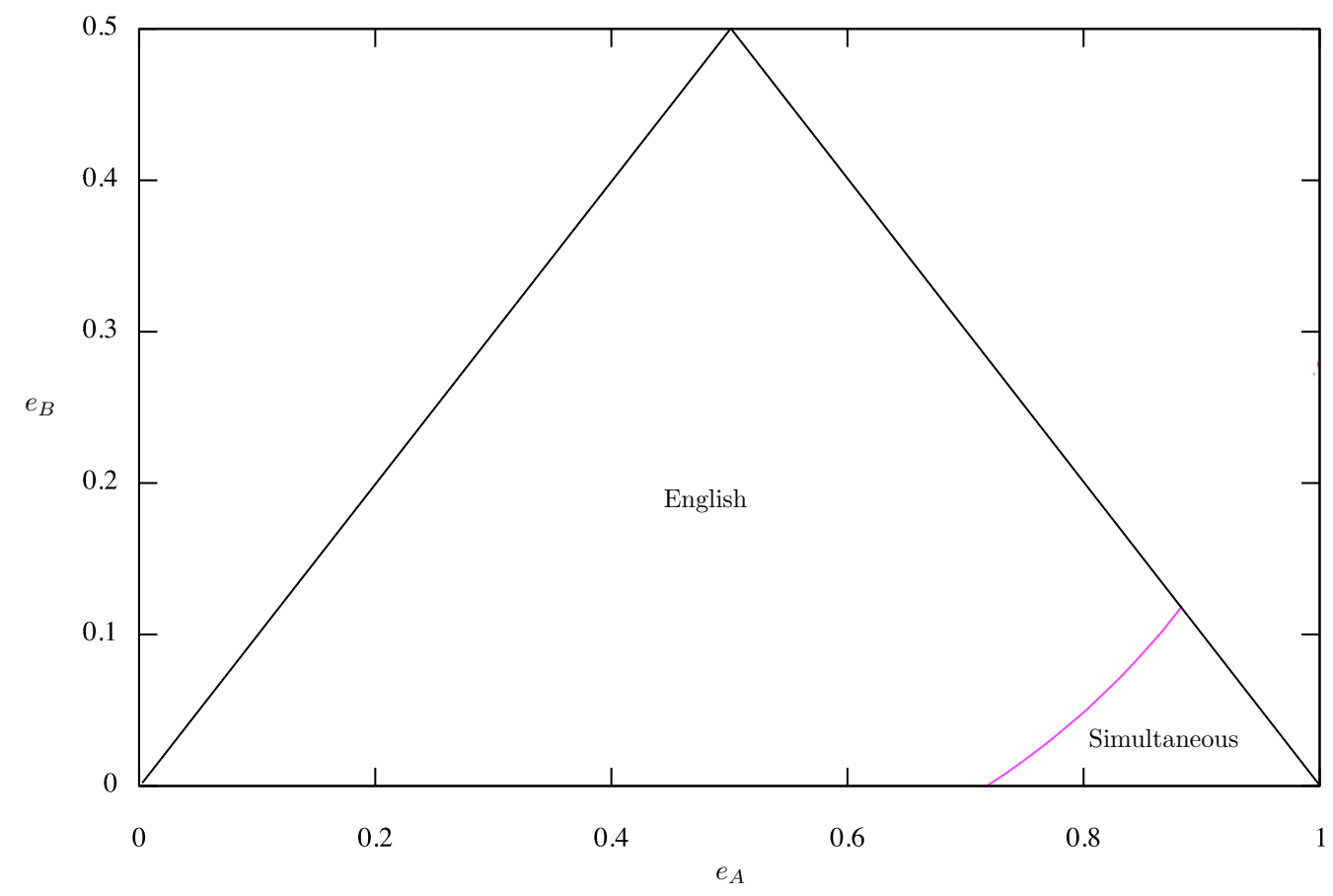

Figure 1: Comparison of the firm's revenue. 


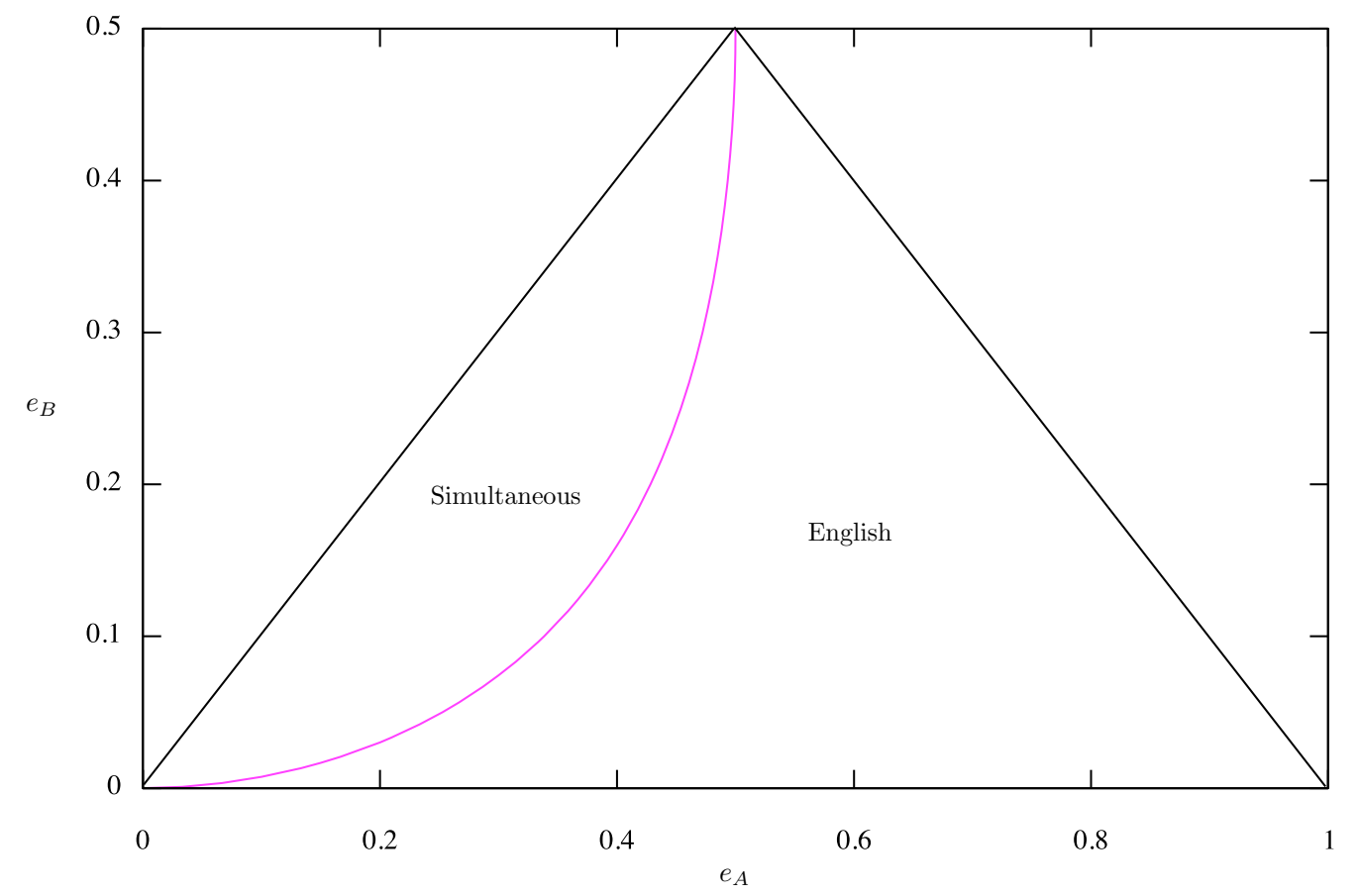

Figure 2: Comparison of country $A$ 's expected welfare. 